\title{
An unusual electrooptical effect observed for DNA fragments and its apparent relation to a permanent electric moment associated with bent DNA
}

\author{
Jan Antosiewicz * and Dietmar Porschke \\ Max-Planck-Institur fï biophysikalische Chemie, 3400 Göttingen, F.R.G.
}

Received 3 June 1988

Revised manuscript received 24 August 1988

Accepted 8 November 1988

DNA bending; Electric dichroism; Hydrodynamics; Bead model șimulation; Dipole moment

Dichroism decay curves of DNA fragments with chain lengths in the range of 179-256 bp show an amplitude inversion suggesting the existence of a positive dichroism component, when these fragments are dissolved at monovalent salt concentrations above approx. $5 \mathrm{mM}$ and are exposed to field pulses with amplitudes and/or lengths above critical values. At the critical values, the unusual dichroism is reflected by an apparent acceleration of the decay curves, which can be fitted by single exponentials with time constants much below the values expected from the DNA contour lengths. The critical pulse amplitudes and lengths decrease with increasing DNA chain length and increasing salt concentration. The experimental data are consistent with results obtained by hydrodynamic and electric model calculations on smoothly bent DNA double helices. The DNA is represented by a string of overlapping beads, which is used to calculate the rotational diffusion tensor and the center of diffusion. The distribution of phosphate charges is asymmetric with respect to this center and thus gives rise to a substantial permanent dipole moment. The magnitude of this dipole moment is calculated as a function of DNA curvature and is used together with experimental values of polarizabilities for simulations of dichroism decay curves. The curves simulated for bent DNA show the same phenomenon as observed experimentally. The ionic strength dependence of the unusual dichroism is explained by an independently observed strong decrease of the polarizability with increasing salt concentration. The field strength dependence is probably due to field-induced bending of double helices driven by the change of the dipole moment. Although our calculations are on rigid models of DNA and thus any flexibility of the double helix has not been considered, we conclude that the essential part of our experimental results can be explained by our model.

\section{Introduction}

Electrooptical techniques $[1,2]$ proved to be very useful for the investigation of biological and other macromolecules. Among the biopolymers, double-helical DNA has been investigated most thoroughly by electrooptical measurements [3-5] because of its special biological function, but also because of its unusually large optical and electric anisotropy, which gives rise to easily detectable

Correspondence address: D. Porschke, Max-Planck-Institut für biophysikalische Chemie, 3400 Göttingen, F.R.G.

* On leave from Institute of Experimental Physics, Department of Biophysics, Warsaw University, 02-089 Warsaw, Poland. electrooptical signals. Under most experimental conditions the electrooptical transients observed for various DNA samples are consistent with the expectation based on simple models. However, under some conditions, the observed signals deviate from expectation, which is then usually attributed to special reactions like field-induced denaturation of the double helix [6,7].

In the present investigation we describe a quite unusual electrooptical signal, which has been observed reproducibly for certain DNA fragments under well-defined experimental conditions. We show that the unusual signal cannot be attributed to any of the known field-induced reactions, but is consistent with hydrodynamic and electric model calculations on bent DNA helices. 
Several electrooptical investigations of various DNA samples and in particular of DNA restriction fragments have been reported in the literature [3-13], but either the unusual effect has not been observed or response curves deviating from standard have been discarded as artifacts. Since the unusual effect is mainly induced at high electric field strengths and at relatively high salt concentrations, its observation and investigation require special technical facilities, which are not available everywhere. In our laboratory the unusual response has been observed repeatedly on various accasions, until finally a systematic investigation could no longer be avoided. After much experimental evidence in favor of a special molecular response and against an artifact had been accumulated, the theoretical analysis not only provided an explanation, but also showed that one would have to search for the unusual effect, if not observed previously. Electrooptical data reported previously from this laboratory were not influenced by the unusual effect, because experimental conditions leading to this effect were avoided, for example, by using low electric field strengths and/or short pulses.

\section{Materials and methods}

The effects described below were mainly analyzed for the fragments with 179 and $256 \mathrm{bp}$, which have been prepared as described before [14]. Similar effects have been found for fragments with 187, 203 and $219 \mathrm{bp}$, which were kindly provided by $W$. Hillen, Erlangen. The samples were dialysed extensively, firstly against a buffer containing $1 \mathrm{M} \mathrm{NaCl}, 1 \mathrm{mM}$ sodium cacodylate (pH 7), $1 \mathrm{mM}$ EDTA and finally vs. several changes of $1 \mathrm{mM} \mathrm{NaCl}, 1 \mathrm{mM}$ sodium cacodylate (pH 7), 0.2 mM EDTA (buffer B1). Addition of 5 or $10 \mathrm{mM} \mathrm{NaCl}$ to buffer B1 led to buffers B5 or $B 10$, respectively. The dichroism was measured as described previously [14-16]. Time constants were evaluated by a deconvolution routine [17].

For hydrodynamic simulations we used the following procedures: Rotational diffusion tensors and positions of centers of diffusion were calculated by a program written on the basis of a review article by Garcia de la Torre and Bloomfield [18]. Amplitudes and time constants of the dichroism decay curves were calculated as described by Wegener et al. [19]. The components of the extinction coefficient and electric polarizability tensors were calculated as described previously [20]. For all of our computer calculations we used the facilities of the Gesellschaft für wissenschaftliche Datenverarbeitung mbH, Göttingen.

\section{Results}

\subsection{Unusual dichroism decay curves}

Usually, the electric dichroism of DNA fragments rises monotonically and after pulse termination also decays monotonically without inversion of the slope. During measurements of the electric dichroism under various buffer conditions, we observed dichroism curves, which clearly deviate from the standard response and cannot be explained by any of the effects which have been characterized previously as a cause of unusual dichroism responses. The special response has been observed for DNA fragments with lengths in the range between 179 and $256 \mathrm{bp}$ at ion concentrations around $10 \mathrm{mM}$. The experimental observations may first be described for a fragment with $179 \mathrm{bp}$ in buffer $\mathrm{B} 10$ at $2^{\circ} \mathrm{C}$. Application of relatively low electric field pulses $(<28 \mathrm{kV} / \mathrm{cm}$, at a given pulse length of about $4 \mu \mathrm{s}$ ) induces standard dichroism effects: the optical signal of both rise and decay curves changes monotonically; the decay curves can be described by two exponentials (cf. fig. 1a); the faster process has been attributed to bending and the other to overall rotation of the double helix. When the amplitude of the electric field pulse is increased to $28 \mathrm{kV} / \mathrm{cm}$, the decay process appears to be accelerated. At this point, the dichroism decay can be fitted by a single time constant of $0.57 \mu \mathrm{s}$ to a reasonable degree of accuracy (cf. fig. 1b). When the electric field strength (for a given pulse length) is increased beyond $28 \mathrm{kV} / \mathrm{cm}$, the dichroism decay turns into a more complex form, which suggests the existence of a positive dichroism component (cf. fig. 1c). These decay curves can be fitted by two 

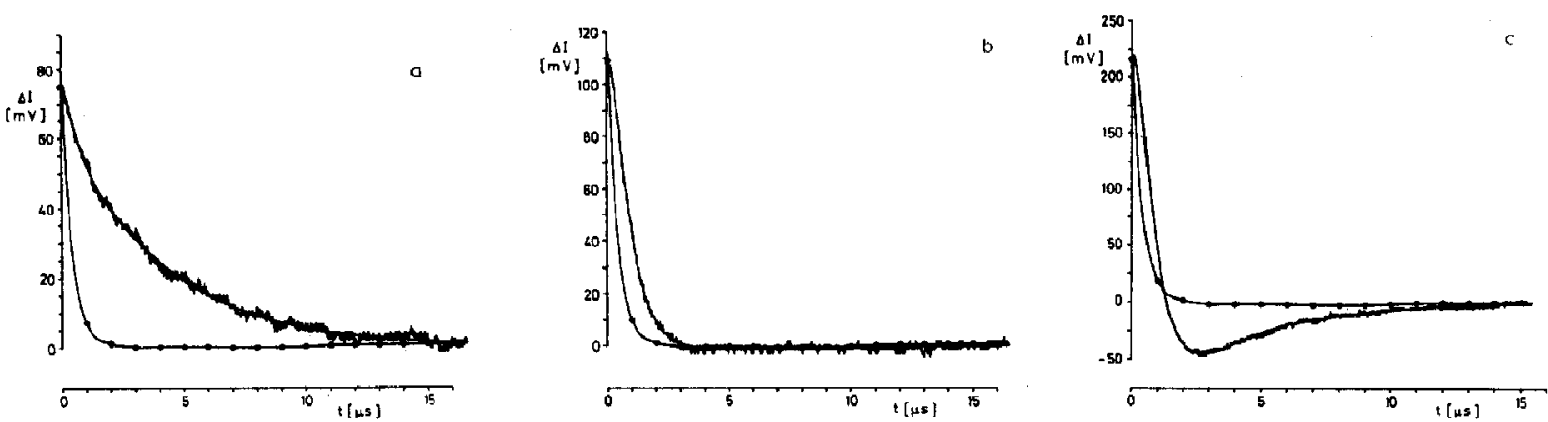

Fig. 1. Dichroism decay curves (change of light intensity $\Delta I$ at $248 \mathrm{~nm}$ at time $t$ after pulse termination) observed for a 179 bp fragment in buffer B10 at $2^{\circ} \mathrm{C}$ after electric field pulses of (a) $15 \mathrm{kV} / \mathrm{cm}$ for $9 \mu \mathrm{s}$, (b) $28 \mathrm{kV} / \mathrm{cm}$ for $14 \mu \mathrm{s}$ and (c) $40 \mathrm{kV} / \mathrm{cm}$ for 14 $\mu$ s. The lines without noise represent least-squares fits using reference curves which are indicated by circles, for deconvolution. The time constants $\tau$ and amplitudes $A$ are: (a) $\tau_{1}=0.22 \mu \mathrm{s}, A_{1}=17 \mathrm{mV} ; \tau_{2}=4.3 \mu \mathrm{s}, A_{2}=57 \mathrm{mV}$; (b) $\tau=0.57 \mu \mathrm{s}, A=109 \mathrm{mV}$; (c) $\tau_{1}=0.60 \mu \mathrm{s}, A_{1}=343 \mathrm{mV} ; \tau_{2}=2.95 \mu \mathrm{s}, A_{2}=-120 \mathrm{mV}$.

exponentials with opposite amplitudes. The fast component with a time constant of approx. $0.6 \mu \mathrm{s}$ is associated with the negative dichroism, whereas the slower component with a time constant of approx. $3 \mu \mathrm{s}$ is associated with the apparent positive dichroism. An increase in electric field strength up to $60 \mathrm{kV} / \mathrm{cm}$ leads to an increase in the apparent positive dichroism component, whereas the time constants do not change within experimental accuracy.

Similar effects were observed for other DNA fragments with chain lengths in the range 179-256 bp. In all cases, the dichroism curves corresponded to the standard at low field strengths, but showed a decrease of the slow decay amplitude with increasing field strength. At a 'critical' field strength, the decay appears to be suddenly accelerated and the decay curve can be fitted by a single exponential with a time constant, which is much shorter than expected from the contour length of the respective DNA fragment. When the field strength is increased beyond the critical value, a component appears in the decay curves, which suggests the existence of a positive dichroism. The amplitude of the component with the apparent positive dichroism increases with electric field strength, but usually does not exceed $50 \%$ of the total amplitude (the total amplitude is defined as the change of the signal from the stationary level in the presence of the electric field to the level at 'infinite' time after pulse termination).
The critical field strength $E_{\mathrm{c}}$ decreases with chain length: in buffer B10 at $20^{\circ} \mathrm{C}$ we observed $E_{\mathrm{c}} \approx 16 \mathrm{kV} / \mathrm{cm}$ for a fragment with $256 \mathrm{bp}$ and $E_{\mathrm{c}} \approx 47 \mathrm{kV} / \mathrm{cm}$ for a fragment with $179 \mathrm{bp}$. Variation of the nucleotide concentration in the range from 5 to $40 \mu \mathrm{M}$ (monomer units) did not lead to a detectable change of the unusual dichroism and thus the effect does not seem to be due to interactions between different DNA helices. However, the unusual dichroism curves proved to be strongly dependent upon salt concentration. At salt concentrations equal to or less than $2.5 \mathrm{mM}$ the unusual dichroism curves have not been observed; at salt concentrations around $7.5 \mathrm{mM}$ (buffer B5, $20^{\circ} \mathrm{C}$ ) the unusual effect appears above a critical field strength of approx. $21 \mathrm{kV} / \mathrm{cm}$ for the fragment with $256 \mathrm{bp}$; the critical field strength for the same fragment is approx. $16 \mathrm{kV} / \mathrm{cm}$ at a salt concentration of approx. $12.5 \mathrm{mM}$ (buffer B10, $20^{\circ} \mathrm{C}$ ).

All of the effects discussed above are also dependent on the length of the applied field pulse. The values given above for a temperature of $20^{\circ} \mathrm{C}$ are valid for relatively short pulse lengths of 3-5 $\mu \mathrm{s}$. The amplitude of the decay component associated with the apparent positive dichroism increases with the duration of the pulse. Unfortunately, it is not possible to derive a time constant for the induction of the unusual effect, because this effect is not yet saturated after electric field pulses of about $10 \mu \mathrm{s}$. Although longer field 
pulses can be applied, long pulses of high electric field strength applied to samples of high salt concentration often induce artifacts due to cavitation, which ultimately may lead to destruction of the measuring cell. The cavitation is of course partly due to heating of the solution; however, the heating effect apparently does not cause the unusual dichroism, because thermal denaturation of DNA, for example, can be excluded (see below).

The unusual effect observed in the decay curves is also indicated in the dichroism rise curves which show an inversion of the amplitude under corresponding experimental conditions. However, the inversion effect is more clearly visible in the decay than in the rise curves. This is due to a relatively slow time constant for the induction of the effect even under high electric field pulses (cf. above). Due to technical difficulties encountered for long electric field pulses, we could not determine the induction time constant from the rise curves.

Since unusual dichroism curves may arise from field-induced conformation changes such as DNA denaturation, we have checked for field-induced reactions. However, measurements at the magic angle $[21,22]$ did not give any indication of a field-induced reaction under the conditions where the unusual dichroism appears. Correspondingly, the dichroism curves recorded for a perpendicular orientation of the polarization plane with respect to the field vector were as expected according to $\Delta A_{\|}(t)=-2 \Delta A_{\perp}(t)$, where $\Delta A_{\perp}(t)$ and $\Delta A_{\|}(t)$ are the absorbance changes for light polarized perpendicular and parallel to the field vector at time $t$, respectively. A comparison with data col-

Table 1

Comparison of experimental and calculated rotational relaxation time constants

Calculations are for overlapping beads with radius $12.7 \AA$ (cf. text).

\begin{tabular}{lll}
\hline $\begin{array}{l}\text { No. of } \\
\text { base pairs }\end{array}$ & \multicolumn{2}{l}{ Relaxation times (ns) } \\
\cline { 2 - 3 } & Calculated & $\begin{array}{l}\text { Measured } \\
(\mathrm{B} 1+10 \mathrm{mM} \mathrm{NaCl})\end{array}$ \\
\hline 69 & 307.6 & 307 \\
84 & 500.6 & 506 \\
95 & 683.5 & 683 \\
\hline
\end{tabular}

lected for field-induced DNA denaturation [7] shows that this reaction should not be expected under the experimental conditions used in the present investigation. In fact, the conditions required for the two effects are opposite: field-induced DNA denaturation is favored at low salt [7], whereas the unusual dichroism described above is favored by high salt. Thus, we have to find an explanation for the unusual dichroism without a major conformation change involving disruption of base pairs.

\subsection{Hydrodynamic and electric model calculations}

\subsubsection{Bead models for hydrodynamic simulation}

For our simulations of DNA rotational diffusion and dichroism decay curves we used procedures discussed in the literature [18-20] and thus we describe the main steps of our simulation only very briefly. DNA double helices are modeled by strings of overlapping beads. The number of equally spaced beads corresponds to the integer of $L / r$, where $L$ is the length of the DNA (number of base pairs $\times 3.4 \AA$ ) and $r$ the radius of the beads. The radius $r$ was adapted to rotational relaxation time constants which were measured for DNA fragments with less than $100 \mathrm{bp}$ in buffer B10. These fragments may be considered as almost rigid and straight. A comparison of measured and simulated time constants is given in table 1. Reasonable agreement has been obtained for a bead radius of $12.7 \AA$, which has been used for all the simulations described below.

\subsubsection{Permanent electric moments of bent DNA molecules}

It is generally accepted that the permanent electric moment of straight DNA double helices is negligible due to symmetry of the distribution of its phosphate charges: However, the symmetry of the double helix is partly lost upon bending and thus a permanent moment may arise for bent DNA molecules. In a first step for the calculation of dipole moments, we apply the standard equation [23]

$\vec{\mu}=\sum_{i} e_{i} \vec{r}_{i}$ 


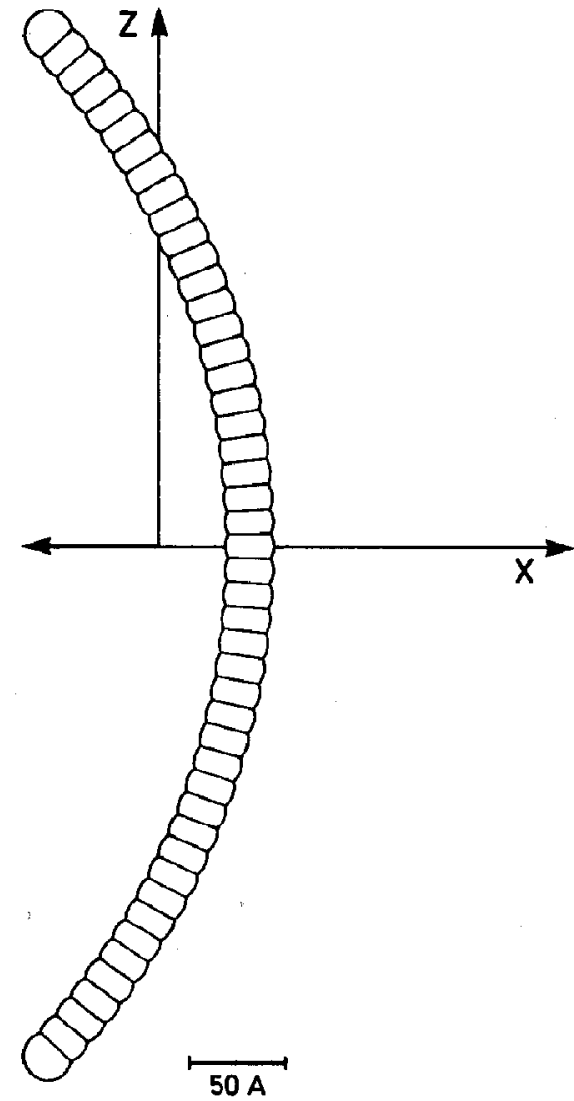

Fig. 2. Bead model of 179 bp DNA fragment with $90^{\circ}$ angle of bending. The center of the coordinate system is located at the center of diffusion (CD). The thick vector shows the orientation of the permanent electric moment of the DNA fragment, relative to $C D$, calculated under the assumption of uniform effective distribution of negative charges along the DNA axis.

which provides a dipole moment $\vec{\mu}$ that is without physical meaning for molecules with a net charge, unless a proper coordinate system is used; $e_{i}$ is the charge on atom $i$ and $\vec{r}_{i}$ its position. In the case of DNA with its large net charge, permanent dipole moments calculated according to eq. 1 have a physical meaning with respect to diffusion only, when referred to the center of diffusion of the macromolecule.

For the calculation of the 'effective' dipole moments we consider a DNA molecule (cf. fig. 2) which is located in the $x z$ plane and bent symmetrically with respect to the $x$-axis. Due to symmetry the components of the permanent dipole moment are zero in the $y$ and $z$ directions. The component in the direction of the $x$-axis may be calculated relative to the center of the DNA arc by an expression which is analogous to eq. 1

$\mu_{x}^{\prime}=\int_{-\Phi / 2}^{+\Phi / 2} R^{2} \sigma \cos (\phi) \mathrm{d} \phi$

where $\sigma$ is the effective charge density along the DNA axis, $R$ the radius and $\Phi$ the bending angle. By integration we obtain

$\mu_{x}^{\prime}=\sin (\Phi / 2) R Q /(\Phi / 2)$

where $Q$ is the total charge of the DNA. The same equation is obtained if we assume separate distribution of positive and negative charges aligned around the arcs with a common center instead of one effective charge density. The effective permanent dipole moment $\mu_{x}$ is calculated relative to the center of diffusion $C D$ according to [23]

$\mu_{x}=\mu_{x}^{\prime}-x_{\mathrm{CD}} Q$

where $x_{\mathrm{CD}}$ is the $x$ coordinate of the position vector of $\mathrm{CD}$ in the initial coordinate system $\left(x_{\mathrm{CD}}\right.$ can be calculated as the difference of the radius of bending and the $x$-coordinate of the central bead

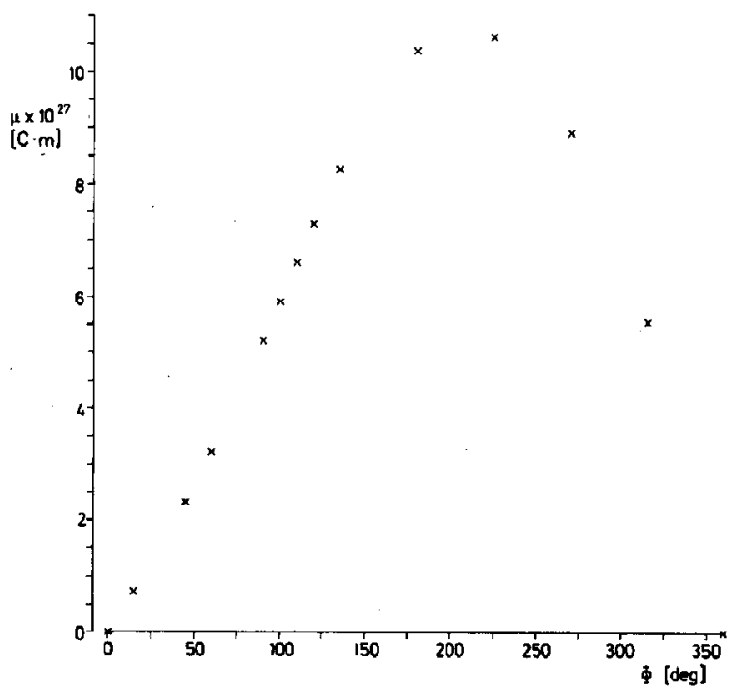

Fig. 3. Dependence of the permanent electric moment of a 179 bp DNA fragment on the angle of bending, assuming $12 \%$ of elementary negative charge as an effective charge on each phosphate of the fragment. 
Table 2

Transient electric dichroism data for a 179 bp DNA as a function of the bending angle

For definition of parameters cf. text. Polarizabilities $\alpha$ are given for straight DNA in units of $\left(10^{-22} \mathrm{~m}^{3}\right)$; effective phosphate charges are given in $\%$ units of the elementary charge $e$; data at $20^{\circ} \mathrm{C}$.

\begin{tabular}{|c|c|c|c|c|c|c|c|c|c|c|c|}
\hline \multirow{3}{*}{$\begin{array}{l}\text { Angle } \\
\text { of } \\
\text { bend- } \\
\text { ing } \\
\left({ }^{\circ}\right)\end{array}$} & \multirow{3}{*}{$\begin{array}{l}\text { Radius } \\
\text { of } \\
\text { bend- } \\
\text { ing } \\
\text { (A) }\end{array}$} & \multirow{3}{*}{$\begin{array}{l}\text { Permanent } \\
\text { dipole moment } \\
\text { assuming } \\
Q_{\mathrm{p}}=12 \%_{e} \\
-\mu_{x}\left(\times 10^{27}\right) \\
(\mathrm{C} \text { m) }\end{array}$} & \multicolumn{3}{|c|}{$\begin{array}{l}\alpha=5.751, \text { neglected } \\
\text { permanent moment }\end{array}$} & \multicolumn{3}{|c|}{$\begin{array}{l}\alpha=5.751 \\
Q_{\mathrm{p}}=12 \% e\end{array}$} & \multicolumn{3}{|c|}{$\begin{array}{l}\alpha=5.751 \\
Q_{p}=10 \% e\end{array}$} \\
\hline & & & \multicolumn{2}{|c|}{$\begin{array}{l}\text { Components } \\
\text { of alignment } \\
\text { tensor }\left(\times 10^{12}\right) \\
\left(\mathrm{m}^{2} \mathrm{v}^{-2}\right) \\
\end{array}$} & \multirow{2}{*}{$\begin{array}{l}\text { Relative } \\
\text { ampli- } \\
\text { tude }\end{array}$} & \multicolumn{2}{|c|}{$\begin{array}{l}\text { Components } \\
\text { of alignment } \\
\text { tensor }\left(\times 10^{12}\right) \\
\left(\mathrm{m}^{2} \mathrm{~V}^{-2}\right)\end{array}$} & \multirow[t]{2}{*}{$\begin{array}{l}\text { Relative } \\
\text { ampli- } \\
\text { tude }\end{array}$} & \multicolumn{2}{|c|}{$\begin{array}{l}\text { Components } \\
\text { of alignment } \\
\text { tensor }\left(\times 10^{12}\right) \\
\left(\mathrm{m}^{2} \mathrm{~V}^{-2}\right)\end{array}$} & \multirow[t]{2}{*}{$\begin{array}{l}\text { Relative } \\
\text { ampli- } \\
\text { tude }\end{array}$} \\
\hline & & & $x x$ & $z z$ & & $x x$ & $z z$ & & $x x$ & $z z$ & \\
\hline 0 & & 0 & 0 & 1.26 & 1 & 0 & 1.26 & 1 & 0 & 1.26 & 1 \\
\hline 15 & 2324.7 & 0.739 & 0.01 & 1.25 & $\begin{array}{l}0.100+1 \\
0.248-4\end{array}$ & 0.04 & 1.25 & $\begin{array}{l}0.100+1 \\
0.141-3\end{array}$ & 0.03 & 1.25 & $\begin{array}{l}0.100+1 \\
0.106-3\end{array}$ \\
\hline 45 & 774.9 & 2.332 & 0.06 & 1.20 & $\begin{array}{l}0.998+0 \\
0.216-2\end{array}$ & 0.40 & 1.20 & $\begin{array}{l}0.984+0 \\
0.157-1\end{array}$ & 0.29 & 1.20 & $\begin{array}{l}0.989+0 \\
0.111-1\end{array}$ \\
\hline 60 & 581.2 & 3.224 & 0.11 & 1.15 & $\begin{array}{l}0.993+0 \\
0.729-2\end{array}$ & 0.74 & 1.15 & $\begin{array}{l}0.934+0 \\
0.663-1\end{array}$ & 0.55 & 1.15 & $\begin{array}{l}0.955+0 \\
0.446-1\end{array}$ \\
\hline 90 & 387.4 & 5.209 & 0.23 & 1.03 & $\begin{array}{l}0.956+0 \\
0.441-1\end{array}$ & 1.89 & 1.03 & $\begin{array}{l}0.202+0 \\
0.798+0\end{array}$ & 1.38 & 1.03 & $\begin{array}{l}0.571+0 \\
0.429+0\end{array}$ \\
\hline 100 & 348.7 & 5.914 & 0.27 & 0.99 & $\begin{array}{l}0.928+0 \\
0.718-1\end{array}$ & 2.41 & 0.99 & $\begin{array}{r}-0.599+0 \\
0.160+1\end{array}$ & 1.76 & 0.99 & $\begin{array}{l}0.203+0 \\
0.797+0\end{array}$ \\
\hline 110 & 317.0 & 6.613 & 0.32 & 0.94 & $\begin{array}{l}0.888+0 \\
0.112+0\end{array}$ & 2.99 & 0.94 & $\begin{array}{r}-0.150+1 \\
0.250+1\end{array}$ & 2.18 & 0.94 & $\begin{array}{r}-0.279+0 \\
0.128+1\end{array}$ \\
\hline 120 & 290.6 & 7.296 & 0.37 & 0.89 & $\begin{array}{l}0.832+0 \\
0.167+0\end{array}$ & 3.62 & 0.89 & $\begin{array}{r}-0.182+1 \\
0.282+1\end{array}$ & 2.63 & 0.89 & $\begin{array}{r}-0.686+0 \\
0.169+1\end{array}$ \\
\hline 135 & 258.3 & 8.274 & 0.44 & 0.82 & $\begin{array}{l}0.715+0 \\
0.285+0\end{array}$ & 4.62 & 0.82 & $\begin{array}{r}-0.139+1 \\
0.239+1\end{array}$ & 3.35 & 0.82 & $\begin{array}{r}-0.848+0 \\
0.185+1\end{array}$ \\
\hline 180 & 193.7 & 10.388 & 0.63 & 0.63 & $\begin{array}{l}0.259+0 \\
0.741+0\end{array}$ & 7.22 & 0.63 & $\begin{array}{r}-0.378+0 \\
0.138+1\end{array}$ & 5.21 & 0.63 & $\begin{array}{r}-0.336+0 \\
0.134+1\end{array}$ \\
\hline 225 & 155.0 & 10.633 & 0.74 & 0.52 & $\begin{array}{l}0.517-1 \\
0.948+0\end{array}$ & 7.65 & 0.52 & $\begin{array}{r}-0.129+0 \\
0.113+1\end{array}$ & 5.54 & 0.52 & $\begin{array}{r}-0.120+0 \\
0.112+1\end{array}$ \\
\hline 270 & 129.1 & 8.912 & 0.76 & 0.50 & $\begin{array}{l}0.189-1 \\
0.981+0\end{array}$ & 5.62 & 0.50 & $\begin{array}{r}-0.773-1 \\
0.108+1\end{array}$ & 4.13 & 0.50 & $\begin{array}{r}-0.713-1 \\
0.107+1\end{array}$ \\
\hline 315 & 110.7 & 5.546 & 0.71 & 0.55 & $\begin{array}{l}0.774-2 \\
0.992+0\end{array}$ & 3.27 & 0.55 & $\begin{array}{r}-0.618-1 \\
0.106+1\end{array}$ & 2.02 & 0.55 & $\begin{array}{r}-0.474-1 \\
0.105+1\end{array}$ \\
\hline 360 & 96.9 & 0 & 0.63 & 0.63 & 1 & 0.63 & 0.63 & 1 & 0.63 & 0.63 & 1 \\
\hline
\end{tabular}

given in table 2 ; note that this $x$-coordinate in table 2 refers to the coordinate system shown in fig. 2). The other two components of the dipole vector remain zero after transition of the coordinate system.

For our numerical calculation we used the results of polyelectrolyte theory $[24,25]$ according to which the effective charge of each phosphate residue is reduced to $12 \%$ of $e$ due to ion condensation in buffers with monovalent ions. For comparison we also included calculations with reductions of the effective charges to 10 and $14 \%$. The results of our calculations are shown in fig. 3 and also in table 2. The permanent dipole moment increases with the degree of bending and approaches a maximum at a bending angle of approx. $220^{\circ}$. The magnitude of the permanent moment is considerable: a DNA with $179 \mathrm{bp}$ and with effective charges $Q_{\mathrm{p}}=12 \% e$, which is bent to a half-circle, has a dipole moment of $1.04 \times 10^{-26}$ $\mathrm{C} \mathrm{m}$ (which corresponds to 3114 Debye units).

\subsubsection{Dichroism decay curves with amplitude inver- sion}

For simulations of the DNA dichroism decay we have to consider the polarizability of the dou- 
Table 2 (continued)

\begin{tabular}{|c|c|c|c|c|c|c|c|c|c|}
\hline \multicolumn{3}{|c|}{$\begin{array}{l}\alpha=5.751 \\
Q_{\mathrm{p}}=14 \delta_{e}\end{array}$} & \multicolumn{3}{|c|}{$\begin{array}{l}\alpha=4.450 \\
Q_{\mathrm{p}}=12 \mathrm{e}_{\mathrm{e}}\end{array}$} & \multicolumn{4}{|c|}{$\begin{array}{l}\alpha=8.130 \\
Q_{\mathrm{p}}=12 \% e\end{array}$} \\
\hline \multicolumn{2}{|c|}{$\begin{array}{l}\text { Components } \\
\text { of alignment } \\
\text { tensor }\left(\times 10^{12}\right) \\
\left(\mathrm{m}^{2} \mathrm{~V}^{-2}\right) \\
\end{array}$} & \multirow[t]{2}{*}{$\begin{array}{l}\text { Relative } \\
\text { ampli- } \\
\text { tude }\end{array}$} & \multicolumn{2}{|c|}{$\begin{array}{l}\text { Components } \\
\text { of alignment } \\
\text { tensor }\left(\times 10^{12}\right) \\
\left(\mathrm{m}^{2} \mathrm{v}^{-2}\right)\end{array}$} & \multirow[t]{2}{*}{$\begin{array}{l}\text { Relative } \\
\text { ampli- } \\
\text { tude }\end{array}$} & \multicolumn{2}{|c|}{$\begin{array}{l}\text { Components } \\
\text { of alignment } \\
\text { tensor }\left(\times 10^{12}\right) \\
\left(\mathrm{m}^{2} \mathrm{v}^{-2}\right)\end{array}$} & \multirow[t]{2}{*}{$\begin{array}{l}\text { Relative } \\
\text { ampli- } \\
\text { tude }\end{array}$} & \multirow[t]{2}{*}{$\begin{array}{l}\text { Relaxation } \\
\text { time } \\
\text { (ns) }\end{array}$} \\
\hline$x x$ & $z z$ & & $x x$ & $z z$ & & $x x$ & $z z$ & & \\
\hline 0 & 1.26 & 1 & 0 & 0.98 & 1 & 0 & 1.78 & 1 & 3521 \\
\hline \multirow{2}{*}{0.05} & 1.25 & $0.100+1$ & 0.04 & 0.97 & $0.100+1$ & 0.04 & 1.77 & $0.100+1$ & 3506 \\
\hline & & $0.185-3$ & & & $0.176-3$ & & & $0.105-3$ & 110 \\
\hline \multirow[t]{2}{*}{0.51} & 1.20 & $0.978+0$ & 0.38 & 0.93 & $0.980+0$ & 0.42 & 1.69 & $0.989+0$ & 3387 \\
\hline & & $0.216-1$ & & & $0.204-1$ & & & $0.113-1$ & 164 \\
\hline \multirow[t]{2}{*}{0.97} & 1.15 & $0.902+0$ & 0.72 & 0.89 & $0.909+0$ & 0.79 & 1.62 & $0.955+0$ & 3289 \\
\hline & & $0.982-1$ & & & $0.915-1$ & & & $0.454-1$ & 210 \\
\hline \multirow[t]{2}{*}{2.46} & 1.03 & $-0.832+0$ & 1.84 & 0.80 & $-0.531+0$ & 1.98 & 1,46 & $0.559+0$ & 3030 \\
\hline & & $0.183+1$ & & & $0.153+1$ & & & $0.441+0$ & 327 \\
\hline \multirow[t]{2}{*}{3.18} & 0.99 & $-0.365+1$ & 2.35 & 0.76 & $-0.261+1$ & 2.53 & 1.39 & $0.180+0$ & 2931 \\
\hline & & $0.465+1$ & & & $0.361+1$ & & & $0.820+0$ & 373 \\
\hline \multirow[t]{2}{*}{3.96} & 0.94 & $-0.556+1$ & 2.92 & 0.73 & $-0.427+1$ & 3.13 & 1.32 & $-0.316+0$ & 2826 \\
\hline & & $0.656+1$ & & & $0.527+1$ & & & $0.132+1$ & 420 \\
\hline \multirow[t]{2}{*}{4.80} & 0.89 & $-0.400+1$ & 3.54 & 0.69 & $-0.348+1$ & 3.77 & 1.26 & $-0.727+0$ & 2717 \\
\hline & & $0.500+1$ & & & $0.448+1$ & & & $0.173+1$ & 465 \\
\hline \multirow[t]{2}{*}{6.14} & 0.82 & $-0.196+1$ & 4.52 & 0.63 & $-0.185+1$ & 4.81 & 1.16 & $-0.873+0$ & 2500 \\
\hline & & $0.296+1$ & & & $0.285+1$ & & & $0.187+1$ & 535 \\
\hline \multirow[t]{2}{*}{9.61} & 0.63 & $-0.406+0$ & 7.08 & 0.49 & $-0.402+0$ & 7.48 & 0.89 & $-0.339+0$ & 2047 \\
\hline & & $0.141+1$ & & & $0.140+1$ & & & $0.134+1$ & 719 \\
\hline \multirow[t]{2}{*}{10.15} & 0.52 & $-0.135+0$ & 7.48 & 0.40 & $-0.134+0$ & 7.96 & 0.73 & $-0.121+0$ & 1584 \\
\hline & & $0.113+1$ & & & $0.113+1$ & & & $0.112+1$ & 825 \\
\hline \multirow[t]{2}{*}{7.37} & 0.50 & $-0.814-1$ & 5.44 & 0.38 & $-0.807-1$ & 5.93 & 0.70 & $-0.716-1$ & 1196 \\
\hline & & $0.108+1$ & & & $0.108+1$ & & & $0.107+1$ & 834 \\
\hline \multirow[t]{2}{*}{2.59} & 0.55 & $-0.555-1$ & 2.43 & 0.42 & $-0.608-1$ & 2.88 & 0.77 & $-0.478-1$ & 899 \\
\hline & & $0.106+1$ & & & $0.106+1$ & & & $0.105+1$ & 755 \\
\hline 0.63 & 0.63 & 1 & 0.49 & 0.49 & 1 & 0.89 & 0.89 & 1 & 609 \\
\hline
\end{tabular}

ble helix resulting from the mobility of its ion atmosphere. We simply use experimental values which have been derived from the stationary level of the dichroism measured as a function of the electric field strength and evaluated according to a saturating induced dipole model [5] in the form of a square root approximation [26]. These measurements have been performed in different buffers and showed a strong decrease in polarizability of, e.g., the 179 bp fragment with increasing salt concentration. For our present simulations we used the value $\alpha=3.60 \times 10^{-33} \mathrm{C} \mathrm{m}^{2} \mathrm{~V}^{-1}$ measured in buffer B10. This value corresponds to an average for a distribution of bent DNA helices which is not exactly known. If we assume that the average degree of bending corresponds to bending angles of 60,120 and $180^{\circ}$ we arrive at polarizabilities of 3.94, 5.09 and $7.20 \times 10^{-33} \mathrm{C} \mathrm{m}^{2} \mathrm{~V}^{-1}$, respectively, for a straight helix of $179 \mathrm{bp}$. For these calculations it has been assumed that the polarizability of straight DNA can be decomposed into contributions of small elements, which can be added up linearly and that the polarizability of bent DNA can be approximated by tensorial ad- 


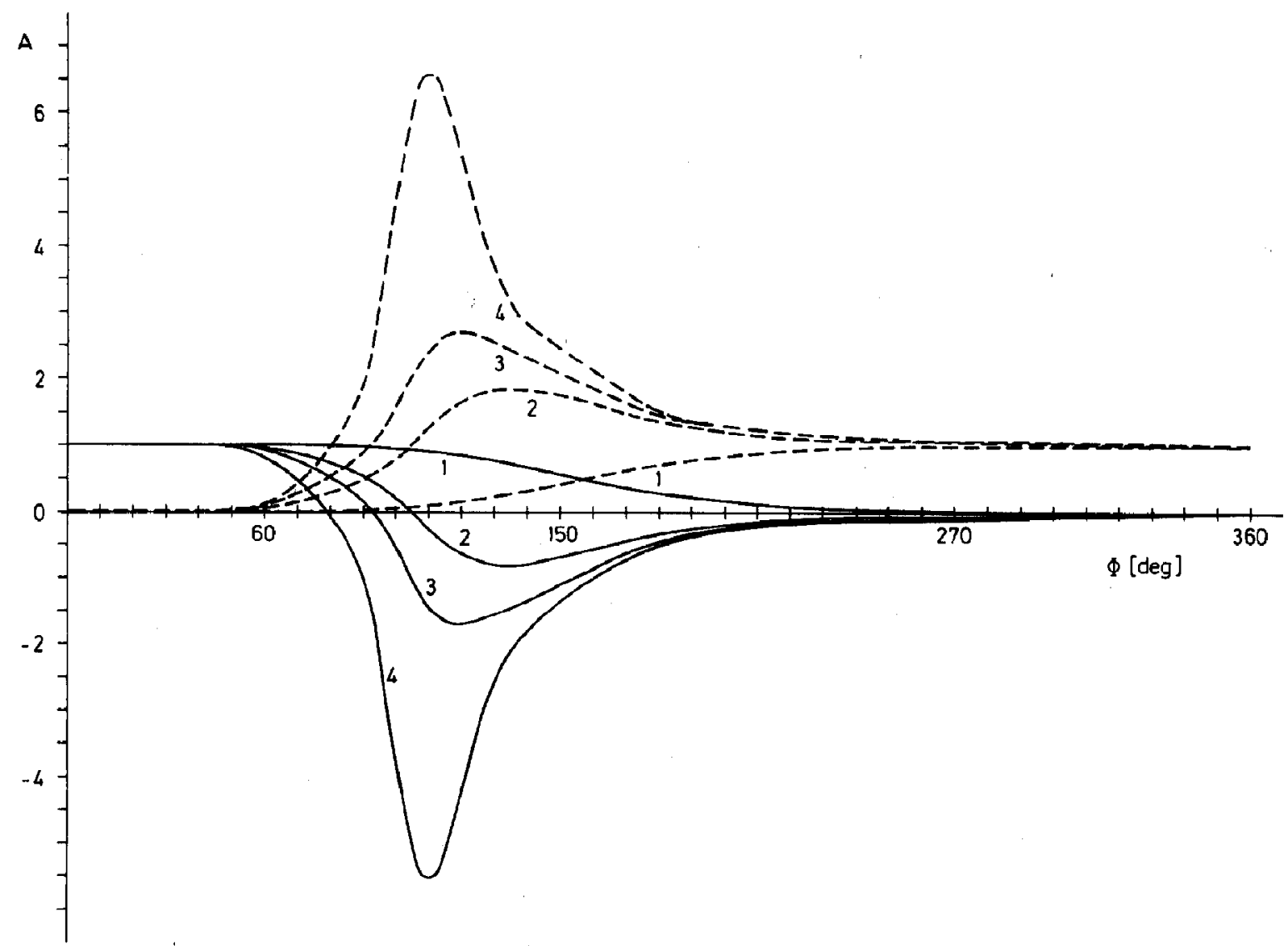

Fig. 4. Relative dichroism amplitudes $A$ for $179 \mathrm{bp}$ fragments as a function of the bending angle $\Phi$ and of the phosphate charge. Solid (broken) lines represent the amplitude of the slow (fast) process. The polarizability is assumed to be $5.09 \times 10^{-33} \mathrm{C} \mathrm{m}{ }^{2} \mathrm{~V}^{-1}$ (cf. text). (1) Contribution from permanent moment neglected; (2-4) effective phosphate charge is assumed to be 10,12 and $14 \%$ of the elementary charge, respectively. Note that in all cases the slow amplitude is dominant at low $\Phi$, the fast amplitude dominating at high $\Phi$.

dition of the element contributions. Since this may be a rather crude approximation for the special case of DNA polarizability, we have simulated dichroism decay curves for 3 different values of the polarizability. To illustrate the degree of orientation caused by the permanent and by the induced dipole moments, we present the components of the alignment tensor calculated according to [19]

$\chi_{i, j}=\beta_{\mu_{i, j}}^{2}+\beta_{\alpha_{i, j}}$

where $\alpha_{i j}$ is the $i, j$ component of the polarizabil- ity tensor; $i, j$ are two of the coordinates $x, y$ or $z ; \beta=1 / k T$.

The dichroism decay of our bent DNA models always shows two components (cf. table 2 and fig. 4). The amplitude of the fast component is always as expected for the case of negative dichroism, which is characteristic for DNA, whereas that of the slow component corresponds to a standard negative dichroism only at small degrees of bending and changes its sign at high degrees of bending. At high polarizabilities the change of sign is observed at relatively high degrees of bending, whereas a high effective charge on the phosphates 


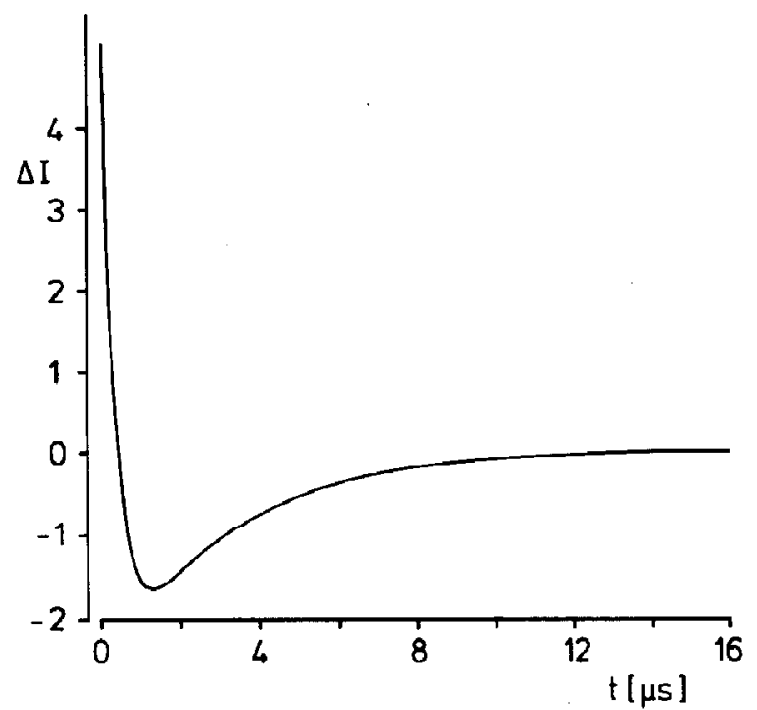

Fig. 5. Dichroism decay curve (change of light intensity $\Delta I$ in arbitrary units as a function of time t) calculated for a $179 \mathrm{bp}$ fragment with a bending angle of $100^{\circ}$ (effective phosphate charge $12 \%$ of elementary charge, polarizability of straight DNA $5.09 \times 10^{-33} \mathrm{C} \mathrm{m}^{2} \mathrm{~V}^{-1} ; 20^{\circ} \mathrm{C}$ ).

corresponding to high permanent moments of bent DNA leads to a change of sign already at relatively low degrees of bending.

The calculated electrooptical decay curves essentially correspond to those observed. An example of a calculated decay curve is given in fig. 5 . The amplitudes of the negative and the positive dichroism components can be adjusted by variation of the curvature and/or the ratio of the induced to permanent dipole contributions. The latter parameter is partly determined by the curvature, but also by the polarizability and the effective charge per phosphate residue.

The amplitudes given in table 2 and figs. 4 and 5 are calculated for the low-field range, where the amplitudes increase essentially with the square of the electric field strength and thus can be calculated relatively easily. Exact calculations at the high electric field strengths used in the experiments require more extensive computations; although the details of the amplitudes would be changed by such computations, the principle would not be affected.

For a comparison of the time constants it should be noted that the experimental curves in fig. 1 have been recorded at $2^{\circ} \mathrm{C}$, whereas the data in table 2 have been calculated for $20^{\circ} \mathrm{C}$. Use of the appropriate conversion factor shows that the time constants calculated for our rigid bead models are clearly higher than the experimental ones. Of course, this is due to the fact that double helices in this range of chain lengths cannot be considered as rigid anymore, but are rather flexible. Part of this problem is discussed in the following section.

\section{Discussion}

Application of electrooptical techniques for the investigation of biopolymers requires knowledge of all essential effects induced by electric field pulses on these biopolymers. This was one of the reasons for the present investigation of the unusual dichroism decay curves observed for DNA fragments. In most cases unusual electrooptical response curves are attributed to field-induced reactions. Stellwagen and O'Konski [6], for example, explained a maximum observed in birefringence rise curves of DNA as being due to field-induced denaturation of the double helices. In the present case there is no indication of any field-induced denaturation, since the absorbance observed at the magic angle does not change and also the solvent requirements for the present unusual effect are not consistent with field-induced denaturation [7].

For our attempts to understand the nature of the unusual effect, model calculations on the electrooptics of bent rods by Mellado and Garcia de la Torre [27] proved to be very useful. These authors have shown that electrooptical decay curves of rods with a bend, e.g., at its center, show a maximum effect under certain conditions with respect to the bending angle and the electric properties. Since the conditions defined by Mellado and Garcia de la Torre are not realistic for the case of DNA, we have performed model calculations on electric and hydrodynamic properties of DNA fragments. We assumed smooth bending of the double helix, since this is the most likely mode of DNA bending. For hydrodynamic simulations of smoothly bent DNA we used procedures estab- 
lished by Garcia de la Torre and Bloomfield [18] and others, which enabled us to define the hydrodynamic center of diffusion and to calculate permanent dipole moments. At first glance, the resulting dipole moments are surprisingly high, but of course deviations from a symmetric distribution of charges over the large dimensions of DNA molecules inevitably lead to large dipole moments. Our model calculations also show that the magnitude and direction of the permanent dipole are appropriate for explanation of the unusual dichroism curves.

We cannot present a simple scheme which illustrates the origin of the unusual dichroism effect at first sight. Obviously, the effect is due to partial orientation of bent molecules with their $x$-axis (cf. fig. 2) parallel to the electric field. Upon pulse termination these molecules rotate relatively quickly around their $z$-axis, which leads to a decay contribution as for molecules with a negative dichroism; subsequent overall distribution leads to a decay component which corresponds to a positive dichroism. A more detailed, yet qualitative description is given in fig. 6 and its legend.

For a more complete explanation of the experimental observations we must include independent results on the salt dependence of the polarizability $\alpha$, which is particularly high in the range of chain lengths around $200 \mathrm{bp}$. The $\alpha$ values obtained from stationary dichroism curves for the fragment with 179 bp decrease from $2.36 \times 10^{-32} \mathrm{C} \mathrm{m}^{2} \mathrm{~V}^{-1}$ at $2.5 \mathrm{mM}$ salt, to $8.29 \times 10^{-33} \mathrm{C} \mathrm{m}^{2} \mathrm{~V}^{-1}$ at 7.5 $\mathrm{mM}$ salt and to $3.60 \times 10^{-33} \mathrm{C} \mathrm{m}^{2} \mathrm{~V}^{-1}$ at 12.5 $\mathrm{mM}$ salt (D. Porschke, unpublished data). Thus, the contribution of the induced dipole moment to the alignment tensor decreases strongly with increasing salt, whereas according to polyelectrolyte theory $[24,25]$ the effective charge of DNA phosphate residues and thus also the permanent dipole of bent DNA change relatively little upon variation of the salt. These facts provide a simple explanation for the observation of the unusual effect at high salt and its absence at low salt.

Usually, more information on the electric parameters may be obtained by analysis of the stationary dichroism as a function of the electric field strength. However, in the present case this procedure is not applicable, because the unusual

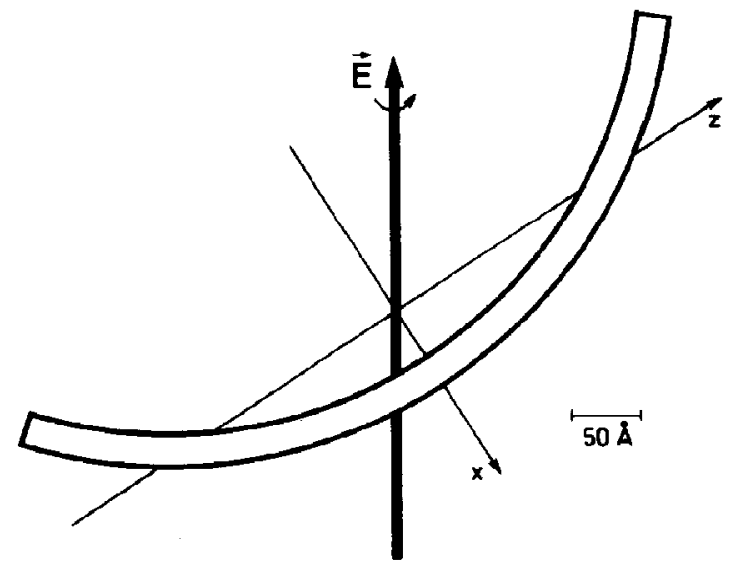

Fig. 6. Stationary alignment of a DNA fragment with 179 bp at a bending angle of $100^{\circ}$ (electric parameters as in fig. 5) induced by an electric field $\vec{E}$. Note that the molecular axes ( $x$ and $z$, cf. fig. 2), the field vector $\vec{E}$ and the curved DNA are all in the same plane. The arrow around the field vector indicates that all positions of the DNA out of the plane, which result from rotation around the field vector, are equally probable. The reduced limiting dichroism calculated for this case is -0.09 . After pulse termination the molecules first rotate relatively quickly around the $z$-axis, which leads to an inversion of the dichroism to +0.05 . Finally, the molecules are distributed randomly (zero dichroism) via relatively slow rotation around the $x$-axis.

phenomenon under investigation does not attain a stationary level during the pulses (pulse lengths are limited due to relatively high conductivities of our solutions).

All our present model calculations are on rigid models, which provide information on the relative magnitude of various contributions to dichroism decay curves. Obviously, DNA molecules are flexible and thus the next step should be calculations on distributions of DNA helices with different degrees of bending. We have not yet extended our calculations in this direction, because electrooptical transients of flexible molecules are particularly difficult to calculate $[27,28]$ and still very much under discussion [29]. However, we should add at least some comments on the problems raised by the flexibility of DNA with respect to the unusual dichroism curves. Since the phosphate charges are arranged symmetrically in straight DNA and non-symmetrically in curved DNA, bent 
forms of DNA are clearly favored in the presence of electric fields due to their dipole moment [30] and thus electric field pulses induce a shift of the bending distribution towards more strongly bent forms of DNA. This effect may be an explanation for the dependence of the unusual dichroism on the electric field strength. The reverse effect is expected from the dipole induced by polarization of the ion atmosphere, which induces stretching of DNA [14]. The relative contribution of these effects depends on the relative size of the dipole moments and thus should be ionic strength dependent. Apparently, electric field pulses induce bending of DNA at relatively high salt concentrations, whereas field-induced stretching of DNA appears to be the main effect at low salt. Since the bending process observed after pulse termination at low salt concentrations is a rather rapid process [14], it is remarkable that the proposed field-induced bending, which apparently gives rise to the unusual dichroism, is a relatively slow process. Probably, the field-induced bending is associated with a relatively slow transition of the DNA conformation. According to our measurements at the magic angle, this transition is not reflected in any large absorbance change.

Another consequence of the flexibility of DNA according to standard views should be relatively rapid motion of DNA segments located at the ends of the DNA chain. If this model is applied to a bent DNA fragment, which has been oriented due to its permanent dipole component by an electric field, we should expect rapid distribution in space of the DNA end segments very soon after pulse termination. At present it is not clear whether the unusual dichroism effect should be visible at all in the presence of such rapid distribution of DNA end segments. In this context it should be mentioned that some experimental results [31] suggest special mechanical properties of double helices. According to these results, stretched or bent DNA does not always return quickly to its equilibrium form and thus DNA end segments may not always be rapidly distributed in space. Further, more detailed model calculations are required on this particular problem.

\section{Acknowledgements}

We wish to thank Jörg Ronnenberg, who did most of the experiments, for expert technical assistance. We are also indebted to Andreas Obst for help in the computations. For these computations we used the facilities of the Gesellschaft für wissenschaftliche Datenverarbeitung, Göttingen.

\section{References}

1 E. Fredericq and C. Houssier, Electric dichroism and electric birefringence (Clarendon, Oxford, 1973).

2 C.T. O'Konski, Molecular electro-optics (Dekker, New York, 1976).

3 D. Ding, R. Rill and K.E. Van Holde, Biopolymers 11 (1972) 2109.

4 M. Hogan, N. Dattagupta and D.M. Crothers, Proc. Natl. Acad. Sci. U.S.A. 75 (1978) 195.

5 S. Diekmann, W. Hillen, M. Jung, R.D. Wells and D. Porschke, Biophys. Chem. 15 (1982) 157.

6 C.T. O'Konski and N.C. Stellwagen, Biophys. J. 5 (1965) 607.

7 S. Diekmann and D. Porschke, Biophys. Chem. 16 (1982) 261.

8 N.C. Stellwagen, Biopolymers 20 (1981) 399.

9 J.G. Elias and D. Eden, Macromolecules 14 (1981) 410.

10 P.J. Hagerman, Biopolymers 20 (1981) 1503.

11 C.H. Lee and E. Charney, J. Mol. Biol. 161 (1982) 289.

$12 \mathrm{X}$. Emonds-Alt, C. Houssier and E. Fredericq, Biophys. Chem. 10 (1979) 27.

13 K. Yamaoka, K. Matsuda and K. Takarada, Bull. Chem. Soc. Jap. 56 (1983) 927.

14 D. Porschke, J. Biomol. Struct. Dyn. 4 (1986) 373.

15 H.H. Grünhagen, Thesis, University of Braunschweig (1974).

16 D. Porschke, Nucleic Acids Res. 8 (1980) 1591.

17 D. Porschke and M. Jung, J. Biomol. Struct. Dyn. 2 (1985) 1173.

18 J. Garcia de la Torre and V.A. Bloomfield, Q. Rev. Biophys. 14 (1981) 81.

19 W.A. Wegener, R.M. Dowben and V.J. Koester, J. Chem. Phys. 70 (1979) 622.

20 J. Antosiewicz and D. Porschke, J. Biomol. Struct. Dyn. 5 (1988) 819.

21 H. Labhart, Chimia 15 (1961) 20.

22 M. Dourlent, J.F. Hogrel and C. Helene, J. Am. Chem. Soc. 96 (1974) 3398.

23 C.J.F. Bottcher, Theory of electric polarisation (Elsevier, Amsterdam, 1973).

24 G.S. Manning, Q. Rev. Biophys. 11 (1978) 179.

25 M.T. Record Jr., C.F. Anderson and T.M. Lohman, Q. Rev. Biophys. 11 (1978) 103. 
26 S. Diekmann, M. Jung and M. Teubner, J. Chem. Phys. 80 (1984) 1259.

27 P. Mellado and J. Garcia de la Torre, Biopolymers 21 (1982) 1857.

28 D.B. Roitman and B.H. Zimm, J. Chem. Phys. 81 (1984) 6348.
29 A. Iniesta and J. Garcia de la Torre, Eur. Biophys. J. 14 (1987) 493.

30 D. Porschke, Annu. Rev. Phys. Chem. 36 (1985) 159.

31 S. Diekmann and D. Porschke, Biophys. Chem. 26 (1987) 207. 